Nuevo fármaco para el tratamiento de la infección por VIH-1

El tratamiento antirretrovírico de uso actual tiene una capacidad limitada para suprimir el virus de la inmunodeficiencia humana (VIH), principalmente debido a su mala penetración en reservorios titulares de VIH, a su toxicidad, a su interacción con otros medicamentos $\mathrm{y}$ al hecho de que muchos pacientes no siguen el régimen terapéutico fielmente. Cuando el virus se sigue replicando en el organismo, se corre el riesgo de que se produzca resistencia a los antirretrovíricos $\mathrm{y}$, posteriormente, el paciente responde menos a medicamentos de esta clase.

En un ensayo clínico reciente efectuado en 48 localidades de Brasil, Canadá, Estados Unidos y México, pacientes que habían recibido por un mínimo de 6 meses un tratamiento con tres clases de antirretrovíricos, y que además mostraban resistencia a varios de estos medicamentos y tenían un mínimo de 5000 copias de ARN de VIH-1 por mililitro de plasma, recibieron enfuvirtida más un régimen óptimo de tres a cinco antirretrovíricos (grupo tratado), o este último régimen solamente (grupo testigo). Al cabo de 24 semanas de tratamiento se observó una reducción de 1,696 $\log _{10}$ copias de ARN por mililitro de plasma en los pacientes tratados con enfuvirtida, frente a una reducción de $0,764 \log _{10}$ en el grupo testigo $(P<0,001)$. El aumento promedio en el recuento de células CD4+ fue de 76 células por milímetro cúbico $\left(\mathrm{mm}^{3}\right)$ y de 32 células por $\mathrm{mm}^{3}$, respectivamente. Noventa y ocho por ciento de los pacientes que recibieron enfuvirtida tuvieron reacciones en el sitio de inyección y las neumonías fueron más frecuentes en este grupo que en el grupo testigo. No obstante, estos riesgos son tolerables cuando se sopesan contra los beneficios antirretrovíricos e inmunológicos del régimen terapéutico con enfuvirtida. Estos resultados coinciden con los del ensayo TORO 2 en Australia y Europa, que fueron presentados este pasado febrero por Greenberg et al. en Boston, Estados Unidos, en la

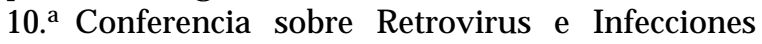
Oportunistas. Los ensayos TORO 1 y 2 han aportado pruebas de que la glucoproteína 41 del VIH-1 es un blanco promisorio en el tratamiento de la infección por VIH-1.

La enfuvirtida o T-20 es un nuevo fármaco sintético peptídico con 36 aminoácidos que se adhiere a la glucoproteína 41 de la cápsula vírica del VIH-1, la misma región capsular que permite la fusión del virus con la membrana de la célula CD4+ del huésped. El medicamento muestra una fuerte capacidad de inhibición selectiva in vitro sin citotoxicidad y es el primer inhibidor de la penetración del VIH en mostrar intensa actividad en personas infectadas por el virus. La enfuvirtida, que es el primero de esta nueva clase de medicamentos antirretrovíricos, podría contribuir de manera importante al tratamiento individualizado de pacientes cuyas opciones terapéuticas se ven limitadas debido a la aparición de resistencia multimedicamentosa. Los resultados del ensayo aquí descrito son preliminares y se realizará un análisis de 48 semanas de duración de los ensayos TORO 1 y 2 para evaluar la durabilidad de la respuesta a la enfuvirtida. (Lalezari et al. Enfuvirtide, an HIV-1 fusion inhibitor, for drugresistant HIV infection in North and South America. New Engl J Med 2003;93(3):380-383.)

\section{Estudio sobre la calidad de la vida de mujeres posmenopáusicas tratadas con estrógenos más progestágenos}

Si bien es cierto que algunos ensayos clínicos apuntan a la presencia de riesgos importantes en asociación con el tratamiento a base de una combinación de estrógenos y progestágenos en mujeres posmenopáusicas, es poco lo que se sabe acerca de los efectos de este tipo de tratamiento hormonal sobre la calidad de la vida de las mujeres tratadas. Con objeto de evaluar este último parámetro, la Women's Health Initiative (WHI) acaba de efectuar un ensayo clínico doblemente cegado en 16608 mujeres entre las edades de 50 y 79 años (edad promedio de 63 años) con el útero íntegro. De ellas, 8 506 fueron tratadas con $0,625 \mathrm{mg}$ de estrógeno equino conjugado más $2,5 \mathrm{mg}$ de acetato de medroxiprogesterona, y 8102 recibieron placebo. Se hicieron determinaciones de la calidad de vida mediante el instrumento de encuesta de 36 parámetros de Rand en todas las mujeres al comienzo del estudio y al cabo de un año, y en un subgrupo de 1511 mujeres al cabo de tres años. Dicha encuesta contiene ocho subescalas que valoran la salud general, el funcionamiento físico, la limitación de las actividades habituales debido a problemas de salud física o de salud mental o emocional, la presencia de dolores corporales, la vitalidad, el funcionamiento 
social y la salud mental o emocional. También se planteó una pregunta aislada para investigar si las mujeres habían notado algún cambio en su salud general durante el último año.

Según los resultados, no se observaron diferencias significativas entre el grupo tratado y el grupo testigo en lo que respecta a salud general, vitalidad, salud mental, estado anímico y satisfacción sexual. Sí se detectó una ligera diferencia significativa en cuanto a la calidad del sueño, el funcionamiento físico y la presencia de dolores corporales al cabo de un año de tratamiento. Al cabo de tres años, sin embargo, no se advirtió diferencia alguna en ninguno de los parámetros estudiados. En mujeres de 50 a 54 años de edad con síntomas vasomotores moderados a graves al principio del estudio se observó una ligera mejoría de estos trastornos exclusivamente. En resumen, en el estudio aquí descrito no se detectó ningún efecto beneficioso que fuese clínicamente importante sobre los parámetros que se usaron para definir la calidad de la vida.

Hay quienes sostienen que pueden demorar un año o más en producirse los efectos favorables del tratamiento con estrógenos más progestágenos sobre los aspectos de la calidad de la vida que se ven definidos por la salud. No obstante, los resultados de este estudio no respaldan esta opinión, aunque no hay que descartar la posibilidad de que la ausencia de resultados significativos se haya debido a que al cabo de tres años de estudio la muestra era relativamente pequeña. (Hays J et al. Effects of estrogen plus progestin on health-related quality of life. $N$ Engl J Med 2003;348(19).)

\section{El tabaquismo de los padres y su efecto en la susceptibilidad de hijos menores de un año a las infecciones respiratorias bajas}

Se sabe que la exposición de los niños menores de un año al humo de tabaco se asocia con un mayor riesgo de infecciones respiratorias bajas, tales como bronquitis y neumonía, irritación del árbol respiratorio superior y una ligera pérdida de la función pulmonar, así como con nuevos casos de asma infantil y un aumento de la gravedad de los síntomas en niños que ya son asmáticos. Por consiguiente, se aconseja a los padres que rodeen a sus hijos de un ambiente sin tabaco y a los pediatras se les insta a investigar los hábitos tabáquicos de los padres cuando lleven a los hijos al consultorio después de la primera consulta posnatal.

Se ha demostrado en algunos estudios que la distancia física entre el niño y el padre fumador muestra una correlación con la cantidad de nicotina en la orina del niño; las concentraciones de nicotina urinaria son más bajas cuando los padres no fuman en la misma habitación donde se encuentra el niño. Por otra parte, mientras más bajas las concentraciones de nicotina urinaria, más bajo es el riesgo que corre el hijo de contraer infecciones respiratorias, según lo revelado por algunos estudios. A fin de investigar más a fondo los efectos de fumar cerca del niño sobre su salud respiratoria, un grupo de investigadores en Tasmania realizó un estudio de cohorte de 1988 a 1995 que abarcó a 11070 niños menores de un año. Durante el estudio los padres fueron entrevistados en tres ocasiones después del parto para investigar si fumaban, cuántos cigarrillos fumaba a diario la madre, y si la madre fumaba en la misma habitación donde estaba el bebé o mientras lo cargaba. También se obtuvo información de este tipo con respecto a otros miembros del hogar. En la última entrevista, que fue telefónica, se preguntó si el niño había sufrido catarros, infecciones en el pecho o amigdalitis. Al mismo tiempo se tomaron muestras de orina de 100 niños para determinar, mediante determinaciones de la concentración de nicotina, si era confiable la información proporcionada por los padres acerca de los hábitos tabáquicos en la familia. Se confirmó que sí lo era y se procedió a elegir una submuestra de 4486 niños del sur de Tasmania, a raíz de lo cual se revisaron las historias clínicas de hospitales de la localidad y, mediante un método de vinculación de fichas, se determinó que 416 niños de la muestra habían sido ingresados en algún momento por una infección respiratoria aguda. Se calculó el riesgo de dicha infección como el porcentaje de niños que fueron ingresados por una infección respiratoria aguda durante los primeros 12 meses de vida.

Según los resultados, en la cohorte estudiada $7,8 \%$ de los niños fueron hospitalizados por una infección respiratoria durante el primer año de vida. En la quinta semana posnatal, $48,6 \%$ de las madres fumaban y sus hijos menores de un año tenían un riesgo $50 \%$ mayor de padecer una infección respiratoria que los hijos de madres que no fumaban. El riesgo aumentaba en proporción con la cantidad de cigarrillos fumados al día por la madre y también en proporción con el número de fumadores en el hogar ( $P$ de la tendencia $<0,001)$, siendo mayor esta última tendencia, aunque no estadísticamente significativa, cuando la madre misma no fumaba. El riesgo aumentaba en relación directa con el número de cigarrillos fumados diariamente por otros miembros del hogar distintos de la madre $(P$ de la tendencia $=$ 0.036) y fue mayor en los hogares que tenían menos habitaciones por morador.

De las madres que fumaban, $71,8 \%$ dijeron que a veces o por costumbre fumaban en la misma habitación donde estaba el bebé, y esta conducta se observó con más frecuencia entre mujeres más jóvenes y entre las que fumaban un mayor número de cigarrillos al día. Los hijos de madres que fumaban en 